\title{
Four Common Insects of Durum Wheat Cultivations in Western Macedonia, Greece
}

\author{
P. N. Deligeorgidis, N. P. Deligeorgidis, C. G. Ipsilandis, \\ A. Vardiabasis, M. Vayopoulou, L. Giakalis, and G. Sidiropoulos \\ Department of Crop Production, Technological Education Institute of Western Macedonia/Branch of Florina, \\ Terma Kontopoulou, 53100 Florina, Greece \\ Correspondence should be addressed to P. N. Deligeorgidis, tm00078@kozani.teikoz.gr
}

Received 21 October 2011; Accepted 10 November 2011

Academic Editor: J. S. Swanston

Copyright ( $) 2012$ P. N. Deligeorgidis et al. This is an open access article distributed under the Creative Commons Attribution License, which permits unrestricted use, distribution, and reproduction in any medium, provided the original work is properly cited.

The purpose of this study was to monitor population fluctuations of various species of Diptera during the growing season of durum wheat, in years 2009 and 2010. The most abundant Hymenoptera species was also included in the study as a control species. The species studied were Cephus pygmaeus, Haplodiplosis marginata, Mayetiola destructor, and Chlorops pumilionis. Samplings of insects were taken in eight periods to cover the late stages of durum wheat. Measurements were made every about $100 \mathrm{~m}$ in the field, with five wheat plants per sample, from 10 different places. Total insect individuals on each wheat plant were counted. Maximum number of individuals per plant reached 6-7 insects, except for C. pumilionis which showed only 3-5 individuals. Year X sampling period interaction was also found in some cases, indicating different populations' fluctuations across years. The relatively low populations found in our study may indicate low level of danger on crop production, but the unstable populations of the most multitudinous insect species $H$. marginata and C. pygmaeus may cover a possible danger, especially for species $H$. marginata which, in specific years, can be found in great numbers causing severe damages on wheat crops. Combination of pests may result in significant damages and a total recording procedure must be practiced.

\section{Introduction}

Durum wheat (Triticum durum $=$ T. turgidum L.) is one of the most important cultivations worldwide and in some specific regions in Greece, like Thessaly and Macedonia. Wheat cultivations in Northern Greece (Macedonia) sometimes suffer pest damages from various insect species $[1,2]$, but in general these damages are not significant and crop production is relatively stable [3].

Order Diptera includes many important species of insects like common flies or the herbivorous species Ceratitis capitata (Wiedemann), which causes severe damages in many different plant species. Other insect species like Hymenoptera are reported in small populations in cereals [1]. Deligeorgidis [2] reported two thrips species in durum wheat cultivations, but their populations were considered low to cause significant damage on wheat's yield.

Haplodiplosis marginata (von Roser) (Diptera: Cecidomyiidae) is widespread in Europe and may harm many species of cultivated and wild cereal plants [4-6]. Mayetiola destructor (Say) (Diptera: Cecidomyiidae), the hessian fly or barley midge, is a very important pest of cereal crops including wheat, rye, and barley [7]. Though a native species of Asia it was introduced in Europe and later in North America. It mainly attacks the stem, although if it is really hungry it will eat any part of the plant it can find. Chlorops pumilionis Bjekander $=C$. taeniopus (Diptera: Chloropidae) is widespread in South, North, Central Europe, North America, Africa, and Japan. The insect is cold resistant and may harm 18 species of cultivated and wild cereal plants, such as winter and spring wheat, winter and spring barley, rye, oats, timothy grass, and couch grass [8-10]. In some cases the insect prefers wheat, in others, barley. Two types of damage are known. The first type appears with a late sowing date. Larvae injure young tissues of plants, including growing points. The stem deforms, internodes stop growing, ear does not emerge. In early sowing cultivations, reaching young ears, the larva 
TABle 1: Meteorological data in the experimental area: Mean air temperature (temp) in ${ }^{\circ} \mathrm{C}$, days of rain, Mean relative (Rel.) humidity (\%), for the three months of monitoring in years 2009 (09) and $2010(10)$.

\begin{tabular}{lccc}
\hline Month & Mean air temp & Days of rain & Rel. humidity \% \\
\hline April 09 & 11.4 & 3 & 60 \\
May 09 & 16.5 & 3 & 50 \\
June 09 & 19.3 & 3 & 48 \\
April 10 & 11.7 & 5 & 62 \\
May 10 & 16.1 & 5 & 62 \\
June 10 & 19.4 & 5 & 50 \\
\hline
\end{tabular}

Data Source: http://www.meteo.gr/.

comes down to tiller base and eats slender parts. Late sowing date is not a common practice for wheat cultivations in Greece.

Cephus pygmaeus L. (Hymenoptera: Cephidae) is widespread in Western Europe, Northern Africa, the Middle East, and also, introduced into Canada and the USA. Flights of adults usually coincide with the beginning of flowering of white acacia, and maximum insect numbers occur during ear formation by winter wheat and during the tillering of spring wheat. Additional feeding occurs for 5-6 days on flowers of crucifers and composites. After completion of feeding, the larva saws stem from inside at the height of a few centimeters above tillering node, plugs the stem up with a cork made of sawdust, and weaves a thin, semitranslucent and waterproof cocoon, where it overwinters [11].

The purpose of this study was to define and monitor population fluctuations of various species of Diptera during the growing season of durum wheat, in years 2009 and 2010. During monitoring, a few Hymenoptera species were recorded and finally, one, the most abundant, was included in the study as a control species for comparison reasons [2].

\section{Materials and Methods}

This study was conducted in the prefecture of Kozani (region of Western Macedonia, Greece), in durum wheat cultivations of the variety Bronde, in a one-hectare field during the years 2009 and 2010. Only four insect species were found (in significant populations) and defined according to taxonomy keys: Cephus pygmaeus L. (Hymenoptera: Cephidae), Haplodiplosis marginata (von Roser) (Diptera: Cecidomyiidae), Mayetiola destructor (Say) (Diptera: Cecidomyiidae), and Chlorops pumilionis Bjekander $=C$. taeniopus (Diptera: Chloropidae).

Meteorological data are also provided for the experimental area: ELEVATION $637 \mathrm{~m}$, LAT $40^{\circ} 47^{\prime} 12^{\prime \prime} \mathrm{N}$, and LONG $21^{\circ} 25^{\prime} 13^{\prime \prime} \mathrm{E}$ (Table 1 and Figure 1).

Measurements were carried out during the growing season of wheat at late stages, for year 2009 sampling started from 27 of April and lasted until 15 of June and for year 2010 from 30 of April to 18 of June. Samplings of insects were taken in eight periods (every week) to cover the late stages of wheat. Measurements were made every about $100 \mathrm{~m}$ in the field, with five wheat plants per sample, from 10 different

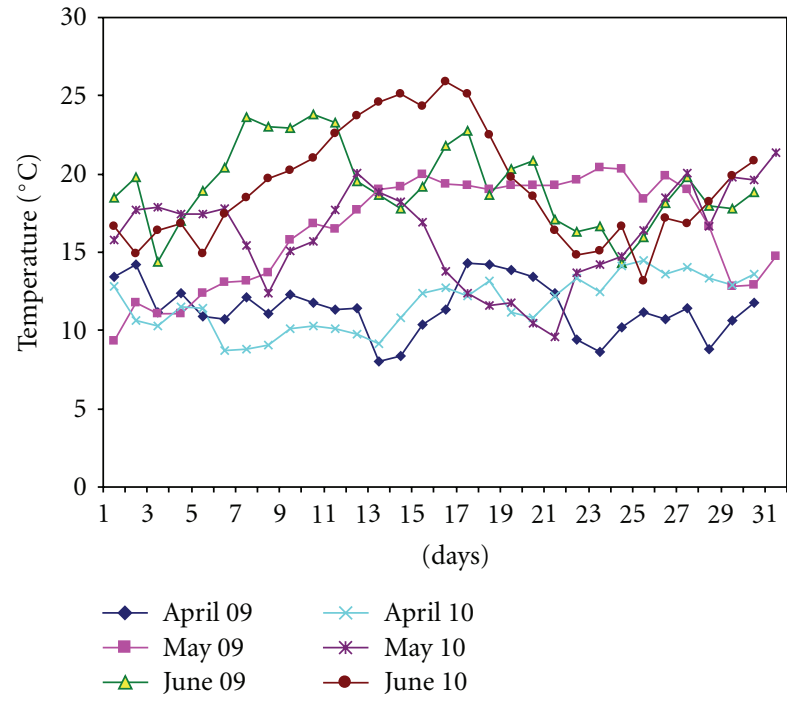

Figure 1: Temperature (in ${ }^{\circ} \mathrm{C}$ ) fluctuations in daily basis for the three months of monitoring (April, May, and June) in years 2009 (09) and 2010 (10).

places (replications) in the field. Total insect individuals (per species) on each wheat plant were counted according to Deligeorgidis et al. $[12,13]$. The average value of the five plants was used in calculations to make data more representative and suitable for statistical analysis (with no transformations and absence of nested analysis). ANOVA was performed in SPSS 17.0 according to Snedecor and Cochran [14], analyzing the following factors: year and sampling period (separately for each insect species).

\section{Results}

Meteorological data showed that during May and June temperatures showed different fluctuations between years (Figure 1) and differences in rainy days and relative humidity (Table 1). Also, May of 2010 started warmer but it was a little colder than May of 2009 and this reflects in lower insect populations in some cases (Figure 1).

According to the results presented in Table 2, for all insects studied, sampling period showed the greatest differences (significance level $P<0.00001$ ). This fluctuation is also shown in Figure 2, for all insects species, for the 2 years of study. In the first sampling period insect populations were low reaching maximum between 4 th and 5th period, followed by a considerable decrease in later stages (except for C. pumilionis, which showed relatively stable but low populations until the 6th period of sampling). C. pygmaeus showed some kind of interaction between year and sampling period (Table 2 and Figure 2), but this phenomenon was much more significant in the case of $H$. marginata (which showed also differences of populations between years). Year $\mathrm{x}$ sampling period interaction indicates different kind of populations' fluctuation across years. Insect $C$. pumilionis showed some differences in populations between the two years of monitoring. 
TABLE 2: General mean of insect individuals (GM), sources of variability analyzed, degrees of freedom $(d f)$, and significance level, for the four species: Cephus pygmaeus, Haplodiplosis marginata, Mayetiola destructor, and Chlorops pumilionis.

\begin{tabular}{llcc}
\hline Species & $\begin{array}{l}\text { Source of } \\
\text { variability }\end{array}$ & $d f$ & $\begin{array}{c}\text { Significance } \\
\text { level }\end{array}$ \\
\hline Cephus pygmaeus & Year & 1 & 0.66 \\
GM $=0.903$ & $\begin{array}{l}\text { Sampling period } \\
\text { Year X Sampling }\end{array}$ & 7 & 0.00001 \\
& period & 0.09 \\
\hline $\begin{array}{l}\text { Haplodiplosis marginata } \\
\text { GM }=0.985\end{array}$ & $\begin{array}{l}\text { Year } \\
\text { Sampling period }\end{array}$ & 7 & 0.001 \\
& $\begin{array}{l}\text { Year X Sampling } \\
\text { period }\end{array}$ & 7 & 0.0001 \\
\hline Mayetiola destructor & Year & 1 & 0.414 \\
GM =0.703 & $\begin{array}{l}\text { Sampling period } \\
\text { Year X Sampling }\end{array}$ & 7 & 0.00001 \\
& $\begin{array}{l}\text { period } \\
\text { Year }\end{array}$ & 7 & 0.631 \\
\hline GMlorops pumilionis $=0.334$ & $\begin{array}{l}\text { Sampling period } \\
\text { Year X Sampling }\end{array}$ & 7 & 0.00001 \\
& period & 7 & 0.862 \\
\hline
\end{tabular}

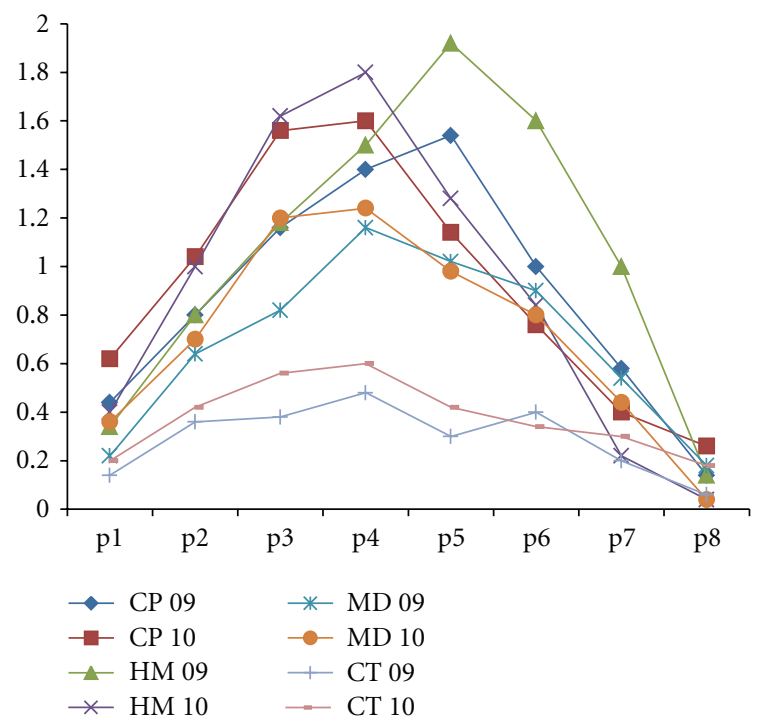

FIGURE 2: Population fluctuations ( $y$-axis: mean number of individuals) across sampling periods (p1-p8), for the four species: $C$. pygmaeus (CP), H. marginata (HM), M. destructor (MD), and $C$. pumilionis $=C$. taeniopus $(\mathrm{CT})$, during the 2 years (2009: 09 and 2010: 10).

Maximum number of insect individuals found on each plant was between 6-7 for the three insect species, except for C. pumilionis which showed a maximum between 3 and 5 individuals (Table 3 ). Total average values were lower, approximately from 0.7 to 1.0 adult insect individuals per plant, except for $C$. pumilionis which showed the lowest values (about 0.3 total average). There were some plants without the presence of any insects.
TABLE 3: Total average and maximum number of individuals counted on host plants, for the four species: Cephus pygmaeus, Haplodiplosis marginata, Mayetiola destructor, and Chlorops pumilionis on durum wheat plants, for each year (2009-2010).

\begin{tabular}{lcc}
\hline Species and year & Total average & Maximum \\
\hline 2009 Cephus pygmaeus & 0.883 & 6 \\
2010 Cephus pygmaeus & 0.923 & 7 \\
2009 Haplodiplosis marginata & 1.06 & 6 \\
2010 Haplodiplosis marginata & 0.91 & 7 \\
2009 Mayetiola destructor & 0.685 & 6 \\
2010 Mayetiola destructor & 0.72 & 6 \\
2009 Chlorops pumilionis & 0.29 & 3 \\
2010 Chlorops pumilionis & 0.378 & 5 \\
\hline
\end{tabular}

\section{Discussion}

Sampling period for all insects studied showed the greatest differences as it was expected due to insect biology and cycle $[12,13]$. Statistically significant interaction between year and sampling period indicates different kind of populations' size and fluctuation across years. This unstable behavior present for $H$. marginata (and in a lower level for C. pygmaeus) may be a result of some specific enemies, or host plant reaction $[2,13]$ and the climatic conditions, taking into consideration the temperature fluctuations of May in year 2010 and year $\mathrm{x}$ sample date interaction. Additionally, this rather unstable and unpredictable behavior, especially for the two most abundant insect species may indicate a danger for durum wheat cultivations and in the specific environment of the area (region of Western Macedonia), taking into consideration that increased attacks result into wheat's yield losses [10]. In Greece wheat sowing starts in October and lasts until December and usually early sowing is preferred because wheat plants can develop better, resulting in increased crop production. During early season it seems that young wheat plants can avoid harm by C. pumilionis because of very low number of individuals. Late season damages in wheat cultivations are also, not reported [1], (Department of Agriculture, personal communication). In these conditions of low pest populations, it is expected that year to year fluctuations may vary according to natural enemies' presence in the specific environment of the experimentation area $[2,15-$ $18]$, although it seems that climatic conditions had more significant impact on population fluctuations. We may safely conclude that this species (C. pumilionis) is not an important enemy of wheat in the region of Western Macedonia.

The economic threshold has to be decided in accordance to insect population size [19] and both size and population fluctuations because of the difficulties in predictions [2]. The relatively low populations found in our study may indicate low level of danger on crop production $[9,10]$, but the unstable populations of the most multitudinous insect species $H$. marginata and $C$. pygmaeus may cover a possible danger, especially for $H$. marginata which in specific years can be found in great numbers, causing severe damages to wheat (and other cereal) crops $[4,6]$. This damage danger implies extensive monitoring in order to apply insect control 
techniques in time $[6,10,20]$. Another parameter is realized attacks per plant used by Bryson et al. [10] and Oakley et al. [20] in order to calculate damages on wheat yield. They referred $5 \%$ loses on yield when increased attacks were recorded. Finally, combination of pests may result in significant damages $[2,19]$ and a total recording procedure for all wheat's enemies must be practiced.

\section{References}

[1] C. Th. Buchelos, Insects, pests of cultivated cereals, Agricultural University of Athens, Greece, 1999.

[2] P. N. Deligeorgidis, N. P. Deligeorgidis, C. G. Ipsilandis et al., "Two thrips species in durum wheat cultivations in the region of Western Macedonia, Greece," Journal of Entomology, vol. 8, no. 5, pp. 484-490, 2011.

[3] NSSG, "Agriculture statistical series (Crops yield)," National Statistical Service of Greece. 2008.

[4] V. Skuhravý, M. Skuhravá, and W. J. Brewer, "Ecology of the saddle gall midge Haplodiplosis marginata (von Roser) (Diptera, Cecidomyiidae)," Journal of Applied Entomology, vol. 96, pp. 476-490, 1983.

[5] M. Skuhravá, V. Skuhravý, and W. J. Brewer, “The distribution and long-term changes in population dynamics of gall midges on cereals in Europe (Cecidomyiidae, Diptera)," Cecidological International, vol. 5, no. 1-2, pp. 1-8, 1984.

[6] C. Popov, L. Petcu, and A. Bãrbulescu, "Researches on biology, ecology and control of saddle gall midge (Haplodiplosis marginata von Roser) in Romania," Romanian Agricultural Research, no. 9-10, pp. 67-77, 1998.

[7] D. G. Buntin and P. L. Raymer, "Hessian fly (Diptera: Cecidomyiidae) damage and forage production of winter Wheat," Journal of Economic Entomology, vol. 82, no. 1, pp. 301-306, 1989.

[8] T. Alkhazishvili, "Materials to studying of chloropid gout fly (Chlorops pumilionis Bjerk.)," in Proceedings of Georgian plant protection institute, vol. 10, pp. 50-53, Georgian plant protection institute, Tbilisi, Georgia, 1954.

[9] J. N. Oakley, J. E. B. Young, S. F. B. Cousins, M. Frost, and M. Froment, "Investigation of the biology and control of gout fly (Chlorops pumilionis) in autumn and spring sown cereals," in Proceedings of the Brighton Crop Protection Conference, Pests and Diseases, vol. 2, pp. 709-714, 1990.

[10] R. J. Bryson, J. Alford, and J. Oakley, "Development of guidelines for improved control of gout fly (Chlorops pumilionis) in winter wheat," HGCA, Project Report, no. 372, pp. 1-66, 2005.

[11] H. Muche, "The Cephidae of Erde," Deutsche Entomologische Zeitschrif Neue Folge Band, vol. 28, no. 4-5, pp. 239-295, 1981 (German).

[12] P. N. Deligeorgidis, C. G. Ipsilandis, C. Fotiadou, G. Kaltsoudas, L. Giakalis, and A. Garsen, "Fluctuation and distribution of Frankliniella occidentalis (Pergande) and Thrips tabaci Lindeman (Thysanoptera: Thripidae) populations in greenhouse cucumber and tomato," Pakistan Journal of Biological Sciences, vol. 8, no. 8, pp. 1105-1111, 2005.

[13] P. N. Deligeorgidis, C. G. Ipsilandis, G. Kaltsoudas et al., "Chemical control of Thrips tabaci, Epitrix hirtipennis and Myzus persicae in tobacco fields in Northern Greece," Journal of Entomology, vol. 4, no. 6, pp. 463-468, 2007.

[14] G. W. Snedecor and W. G. Cochran, Statistical Methods, The Iowa State University Press, Ames, Iowa, USA, 7th edition, 1980.
[15] M. W. LaSalle and T. Dale Bishop, "Seasonal abundance of aquatic diptera in two oligohaline tidal marshes in Mississippi," Estuaries, vol. 10, no. 4, pp. 303-315, 1987.

[16] R. Chyzik and O. Ucko, "Seasonal abundance of the western flower thrips Frankliniella occidentalis in the Arava valley of Israel," Phytoparasitica, vol. 30, no. 4, pp. 335-346, 2002.

[17] P. N. Deligeorgidis, N. P. Deligeorgidis, S. Kayoglou et al., "Monitoring and control of Quadraspidiotus perniciosus (Comstock) hemiptera: Diaspididae on apple trees in the prefecture of Florina, Greece," Journal of Entomology, vol. 5, no. 6, pp. 381-388, 2008.

[18] D. G. Stavridis, P. N. Deligeorgidis, A. Gliatis et al., "Cotton production in the presence of Pectinophora gossypiella (Saunders) in Central Greece," Journal of Entomology, vol. 6, no. 1, pp. 49-55, 2009.

[19] H. Larsson, "Economic damage by Limothrips denticornis in rye, triticale and winter barley," Journal of Applied Entomology, vol. 129, no. 7, pp. 386-392, 2005.

[20] J. Oakley, G. Talbot, C. Dyer et al., "Integrated control of wheat blossom midge: variety choice, use of pheromone traps and treatment thresholds," HGCA, Project Report, no. 363, pp. 167, 2005. 


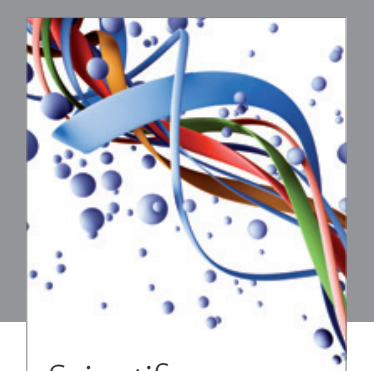

Scientifica
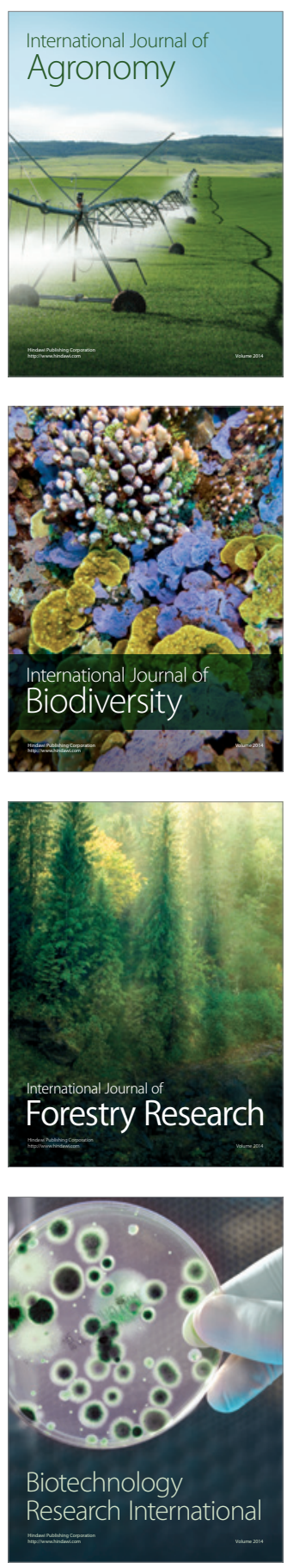
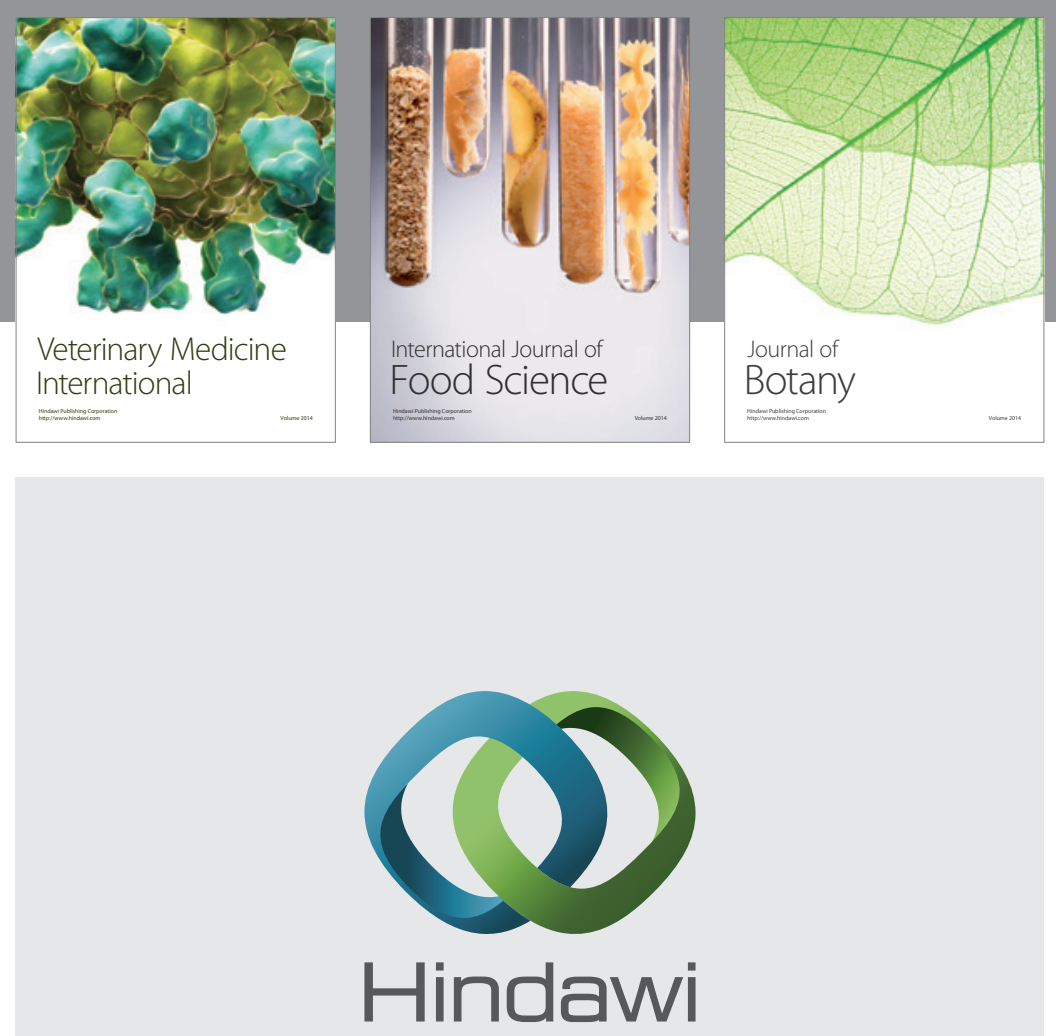

Submit your manuscripts at

http://www.hindawi.com
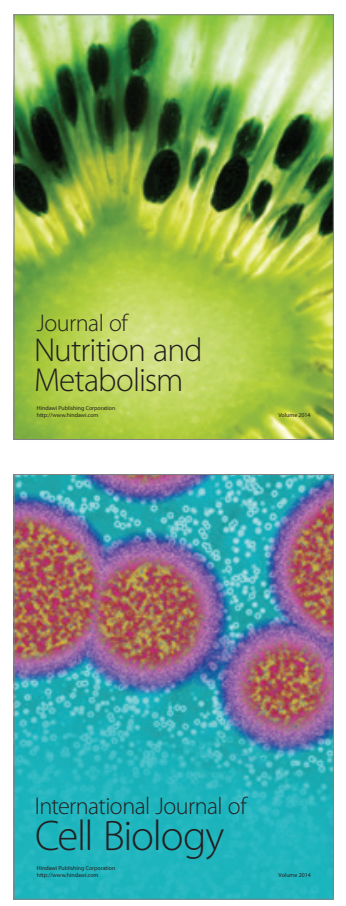
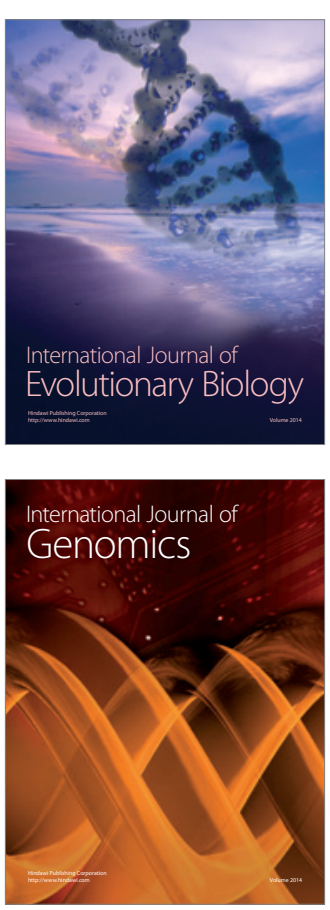
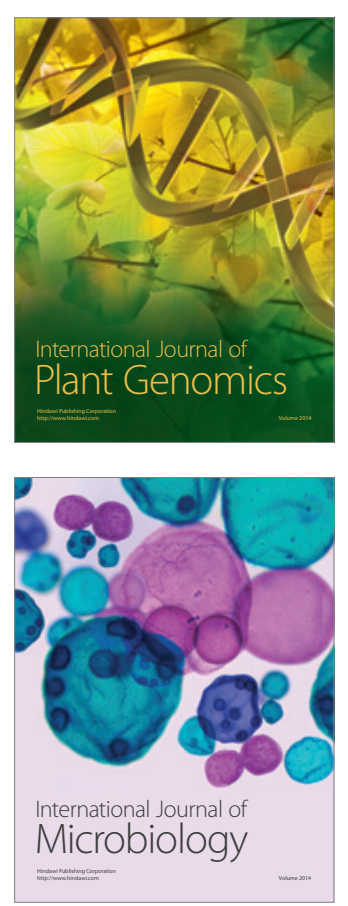

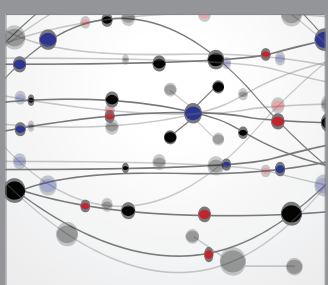

The Scientific World Journal
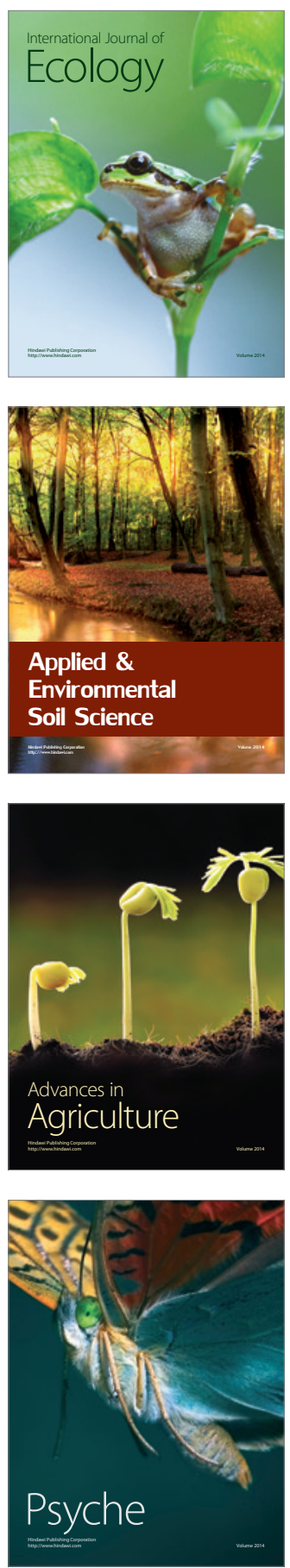